\title{
Developing nurse educators' research capacity in a resource-constrained environment
}

\author{
J E Maritz, ${ }^{1}$ DCur; K Jooste, ${ }^{2} \mathrm{PhD}$ \\ ${ }^{1}$ Department of Health Studies, School of Social Sciences, University of South Africa, Pretoria, South Africa \\ ${ }^{2}$ Department of Nursing Sciences, Faculty of Health and Wellness, Cape Peninsula University of Technology, Cape Town, South Africa
}

Corresponding author:J E Maritz (maritje@unisa.ac.za)

\section{The problem}

Despite concerted efforts through policy reforms, research training and mentorship programmes, nursing research capacity remains low. ${ }^{[1]} \mathrm{A}$ major reform in South Africa is the integration of nursing education with the Ministry of Higher Education and Training, requiring nurse educators to obtain higher degrees. ${ }^{[2]} \mathrm{A}$ revision of the South African Nursing Council (SANC) requirements for registration as a nurse educator includes, among other competencies, the ability to conduct research. ${ }^{[3]}$ The management of a university of technology, where the intervention described here took place, displays a willingness to support researchers. A major constraint, however, is material support related to time available for research due to large teaching loads and remote locations of satellite campuses of the institution. The constrained resource environment also hampers different forms of collaboration necessary for nurse educators' research-capacity development, such as academic, novice-expert, multisite and interprofessional collaboration.

\section{The approach}

The authors launched an experiential and collaborative research-capacity development programme in 2018 (ongoing) that includes nurse educators at the university's central campus in Cape Town and four satellite campuses in Western Cape Province. With a participatory action research approach, the programme participants were not only part of the intervention, but also of the research process, i.e. they were learning in action. This short communication reports on the first two 1-day cycles of the pilot programme at the main campus, where a face-to-face style was followed. Ten participants were divided into 3 small groups. In the first cycle, participants produced drawings of their research experience and research pathway, while the second cycle concentrated on a collaborative data analysis session with a remix of the original team members.

\section{The outcome}

We learnt that the programme had a positive effect on various levels. On an interpersonal level, the reflective notes indicated that the participants enjoyed the participatory nature of the intervention and particularly the sharing and discussion of ideas, learning of multiple opinions and interpretations of the data analysis. On an intrapersonal level, this led to self-reflection regarding some participants' assumptions of research and potential biases. Participants also appreciated that they often shared similar experiences, such as a fear of conducting research. On other occasions, however, they were not on the same page, e.g. during the data analysis. They appreciated spending dedicated time with colleagues, while learning simultaneously. Some found the programme relaxing and fun, while others were continually thinking about the work that was waiting to be done.

Most found the data collection through drawings interesting - they would apply it to their future research. Some found the team data analysis intimidating, as they had to think, interpret and discuss at the same time. In reflection on this research, we realised that not everybody enjoys teamwork. One participant, however, noted that the team approach was a success in this programme. We are also of the opinion that this programme offering can be improved by including remote campuses in similar, but virtual exercises.

\section{Declaration. None.}

Acknowledgements. We thank the institution for permission to conduct the research, as well as the participants for their engagement.

Author contributions. Both authors were involved in data collection and writing of the report.

Funding. None.

Conflicts of interest. None.

\footnotetext{
Chen Q, Tang S, Castro AR. Research capacity in nursing: A concept analysis based on a scoping review. BMJ Open 2019;9(11). https://doi.org/10.1136/bmiopen-2019-032356

National Department of Health. National Policy on Nursing Education and Training. Pretoria: NDoH, 2019 2. National Department of Health. National Policy on Nursing Education and Training. Pretoria: $\mathrm{NDoH}, 2019$.
3. South African Nursing Council. Exit Level Outcomes - Postgraduate Diploma in Nursing Education. Pretoria: SANC, 2019
}

Accepted 6 July 2020

Afr J Health Professions Educ 2020;12(3):97. https://doi.org/10.7196/AJHPE.2020.v12i3.1370 